\title{
Effect of the distal histidine on the peroxidatic activity of
}

\section{monomeric cytoglobin [version 1; peer review: 2 approved]}

\author{
Penny Beckerson, Dimitri Svistunenko, Brandon Reeder
}

School of Biological Sciences, University of Essex, Colchester, Essex, CO4 3SQ, UK

\author{
V1 First published: 07 Apr 2015, 4:87 \\ https://doi.org/10.12688/f1000research.5971.1 \\ Latest published: 07 Apr 2015, 4:87 \\ https://doi.org/10.12688/f1000research.5971.1
}

\begin{abstract}
The reaction of hydrogen peroxide with ferric human cytoglobin and a number of distal histidine variants were studied. The peroxidase activity of the monomeric wildtype protein with an internal disulfide bond, likely to be the form of the protein in vivo, exhibits a high peroxidase-like activity above that of other globins such as myoglobin. Furthermore, the peroxidatic activity of wildtype cytoglobin shows increased resistance to radical-based degradation compared to myoglobin. The ferryl form of wildtype cytoglobin is unstable, but is able to readily oxidize substrates such as guaiacol. In contrast distal histidine mutants of cytoglobin (H81Y and H81V) show very low peroxidase activity but enhanced radical-induced degradation. Therefore, the weakly bound distal histidine appears to modulate ferryl stability and limit haem degradation. These data are consistent with a role of a peroxidase activity of cytoglobin in cell stress response mechanisms.
\end{abstract}

\section{Keywords}

Cytoglobin, distal histidine, peroxide, ferryl, hexacoordinate, peroxidase, monomer

\section{Open Peer Review}

Approval Status

1 2

version 1

07 Apr 2015

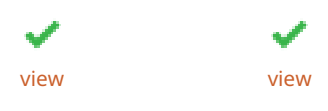

1. Mark Hargrove, Iowa State University, Ames, USA

2. Rakesh Pravinchandra Patel, University of Alabama at Birmingham, Birmingham, USA Any reports and responses or comments on the article can be found at the end of the article. 
Corresponding author: Brandon Reeder (reedb@essex.ac.uk)

Competing interests: No competing interests were disclosed.

Grant information: The author(s) declared that no grants were involved in supporting this work.

Copyright: @ 2015 Beckerson P et al. This is an open access article distributed under the terms of the Creative Commons Attribution License, which permits unrestricted use, distribution, and reproduction in any medium, provided the original work is properly cited. Data associated with the article are available under the terms of the Creative Commons Zero "No rights reserved" data waiver (CC0 1.0 Public domain dedication).

How to cite this article: Beckerson P, Svistunenko D and Reeder B. Effect of the distal histidine on the peroxidatic activity of monomeric cytoglobin [version 1; peer review: 2 approved] F1000Research 2015, 4:87 https://doi.org/10.12688/f1000research.5971.1

First published: 07 Apr 2015, 4:87 https://doi.org/10.12688/f1000research.5971.1 


\section{Introduction}

Cytoglobin (Cygb) is a haem protein ubiquitously expressed in vertebrate cells ${ }^{1,2}$. Cygb has a coordinating distal histidine in the deoxygenated ferrous form, giving a hexacoordinate haem iron similar to neuroglobin $(\mathrm{Ngb})^{1,3,4}$. Several possible physiological functions of Cygb have been proposed including nitric oxide (NO) dioxygenase activity, involvement in collagen synthesis and oxidative stress response ${ }^{5-8}$. The mechanisms by which Cygb affects cellular responses to oxidative stress are unknown, however it has been suggested that protection of cells may occur by Cygb functioning as a scavenger of reactive oxidative species (ROS) or as a peroxidase ${ }^{9,10}$. In vivo studies have shown that Cygb expression is up-regulated by hydrogen peroxide suggesting a role in oxidative stress protection ${ }^{6}$. This is supported by Cygb knockdown studies showing sensitisation of cells to oxidative stress, with overexpression providing protection ${ }^{5}$. The specific role of Cygb in these stress responses is unclear.

The reaction of Cygb with peroxides has not been extensively studied. However, the reactions of pentacoordinate globins, such as myoglobin $(\mathrm{Mb})$ and haemoglobin $(\mathrm{Hb})$, with hydrogen peroxide have been well characterised ${ }^{11,12}$. The reaction of ferrous or ferric $\mathrm{Mb}$ and $\mathrm{Hb}$ with peroxides leads to the formation of the ferryl species $\left(\left[\mathrm{Fe}^{4+}=\mathrm{O}^{2-}\right]^{2+}\right)$. Protein based radicals are also formed in the reaction of ferric $\mathrm{Mb}$ or $\mathrm{Hb}$ with peroxides. Unlike classical peroxidase enzymes, the radical in these systems is inherently unstable leading to oxidative modifications to the haem and protein. In pentacoordinate globins the distal histidine (e.g. H64 in Mb) is important in providing a hydrogen bond to the partially deprotonated bound peroxide $\left(\mathrm{Fe}^{3+}-\mathrm{OOH}^{-}\right)^{13}$. This facilitates the scission of the di-oxygen bond to form the ferryl iron and porphyrin cation radical (Compound I), followed by a rapid migration and partial decay of the radical to form compound $\mathrm{II}^{14-16}$. Proteins that lack the distal residue (e.g. H64Q in Mb) lead to a transient stabilisation of the peroxide-bound intermediate (Compound 0) over the millisecond timescale ${ }^{13,17}$. In Ngb the hexacoordinate configuration of the haem iron prevents the formation of a ferryl species ${ }^{18}$.

This study examines the mechanism of the interaction of Cygb with peroxide and the role of the distal histidine in such reactions. Our data show that the monomeric wildtype (WT) Cygb, when reacting with peroxides, is characterised by a high peroxidase activity (in comparison to other globins) and that the ferryl formed (compound II) is more unstable than seen in $\mathrm{Mb}$ or $\mathrm{Hb}$. The distal histidine is particularly important for this peroxidase activity since the mutants lacking this residue show a low substrate oxidation and high rates of haem degradation. This study supports a role of Cygb peroxidase activity in stress responses in vivo.

\section{Materials and methods}

\section{Cytoglobin engineering, expression and purification}

The human Cygb gene was purchased from OriGene (via Cambridge Bioscience, UK), transferred from the cloning vector into expression vector pET28a (Merck Millipore, UK), expressed and purified as previously described ${ }^{19,20}$. Cygb pET28a plasmid was mutated using site-directed mutagenesis based on a modified Agilent Quikchange II method to give the H81V and H81Y mutation. Initial denaturation was $95^{\circ} \mathrm{C}$ for 2 min followed by 20 cycles of $95^{\circ} \mathrm{C}$ for $50 \mathrm{~s}$, $55^{\circ} \mathrm{C}$ for $60 \mathrm{~s}$ and $68^{\circ} \mathrm{C}$ for $13 \mathrm{~min}$. Primers were purchased from Eurofins, UK. The mutated Cygb were also expressed and purified using the same protocol as for the wildtype (WT) protein ${ }^{19}$. The monomeric, dimeric and polymeric Cygb were separated using G75 Superdex column (GE Healthcare) equilibrated with $0.1 \mathrm{M}$ sodium phosphate buffer (Fischer, UK) pH 7.4. Fractions were collected corresponding to absorbance peaks at $280 \mathrm{~nm}$. Monomeric Cygb variants were used for all subsequent experiments.

\section{UV-Vis spectroscopy}

A Varian Cary 5E UV-vis spectrophotometer was used to measure UV-visible spectra. Extinction coefficients of the Cygb distal histidine mutants were calculated as previously described using HPLC $^{20}$.

Far UV CD spectra of monomeric WT, H81V and H81Y Cygb $(5 \mu \mathrm{M})$ in $20 \mathrm{mM}$ sodium phosphate buffer ( $\mathrm{pH}$ 7.4) were measured using an Applied Photophysics Chirascan CD spectrophotometer between wavelengths $180-300 \mathrm{~nm}$ in a $1 \mathrm{ml}$ quartz cuvette at $20^{\circ} \mathrm{C}$. Scan speed was $60 \mathrm{~nm} \mathrm{~min}{ }^{-1}$. Three spectra were taken and averaged and corrected for buffer baseline.

\section{Peroxidase activity assay}

Monomeric WT, H81V and H81Y Cygb $(5 \mu \mathrm{M})$ in $0.1 \mathrm{M}$ sodium phosphate buffer $\mathrm{pH} 7.4$ were reacted with hydrogen peroxide $(5 \mathrm{mM})$ in the presence of $8.94 \mathrm{mM}$ guaiacol $(0.1 \% \mathrm{v} / \mathrm{v}$, Sigma, UK). The peroxidase activity of Cygb was monitored by the formation of tetraguaiacol $(470 \mathrm{~nm})$ due to the oxidation of guaiacol by the ferryl iron (equation 1):

$$
4 \text { Guaiacol }+4 \mathrm{H}_{2} \mathrm{O}_{2} \stackrel{\text { Globin }}{\longrightarrow} \text { Tetraguaiacol }+8 \mathrm{H}_{2} \mathrm{O} \text {. }
$$

The reaction was followed using an Agilent 8453 diode array spectrophotometer.

\section{Reactions of cytoglobin with hydrogen peroxide}

Ferric monomeric WT, H81V and H81Y Cygb $(50 \mu \mathrm{M})$, in $20 \mathrm{mM}$ phosphate buffer ( $\mathrm{pH} 7.4$ ), were reacted with a range of hydrogen peroxide (Sigma, UK) concentrations $(0-5 \mathrm{mM})$ and incubated at room temperature for 18 hours. The samples were analysed by both non-reducing (4\% stacking, $12 \%$ resolving) and reducing SDSPAGE (4\% stacking and $12 \%$ resolving) gel electrophoresis.

Oxidative damage to the haem in these samples was measured by reverse phase HPLC using an Agilent HP1100 HPLC fitted with a diode array spectrophotometer. The column used was a Zorbax StableBond 300SB C3 $250 \mathrm{mM} \times 4.6 \mathrm{mM}$ fitted with a $12 \mathrm{~mm} \times$ $4.6 \mathrm{~mm}$ guard column. Solvent A was $0.1 \%$ trifluoroacetic acid (TFA) (Fisher, UK) and solvent B was acetonitrile (VWR, UK) containing $0.1 \%$ TFA. The gradient started at $35 \%$ solvent B for $10 \mathrm{~min}$, increasing to $37 \%$ for $5 \mathrm{~min}$, increasing to $40 \%$ for 1 minute with a final increment to $43 \%$ for $10 \mathrm{~min}$. The flow rate was $1 \mathrm{ml} \mathrm{min}{ }^{-1}$ and the temperature was $25^{\circ} \mathrm{C}^{21}$. The haem concentration was calculated from the area under the peak at $\sim 14 \mathrm{~min}$.

The kinetics of the formation of ferryl Cygb was measured using an Applied Photophysics SX20 stopped-flow spectrometer fitted with a diode array unit. Ferric monomeric WT, H81V and H81Y Cygb 
( $5 \mu \mathrm{M}$ after mixing, in $50 \mathrm{mM}$ sodium phosphate buffer $\mathrm{pH} 7.4$ ) were rapidly mixed with a range of hydrogen peroxide concentrations ( $0-10 \mathrm{mM}$ final). Absorbance changes following mixing were recorded using the proSX software and kinetics fitted globally using the Applied Photophysics ProKinetist software.

\section{Electron paramagnetic resonance spectroscopy}

Monomeric WT, H81V and H81Y Cygb $(80 \mu \mathrm{M})$ in $20 \mathrm{mM}$ sodium phosphate buffer ( $\mathrm{pH}$ 7.4) were reacted with hydrogen peroxide, either at $1: 1$ at $(80 \mu \mathrm{M})$ or $1: 10(800 \mu \mathrm{M})$ protein:hydrogen peroxide ratio in Wilmad SQ EPR tubes (Wilmad Glass). The reaction was halted by flash-freezing in dry ice cooled methanol at various time points $(0,20,45,90,180 \mathrm{~s})$. The samples were stored in liquid nitrogen $(77 \mathrm{~K})$ prior to measurement. Electron paramagnetic resonance (EPR) spectra were taken using a Bruker EMX EPR spectrophotometer (X-band) equipped with a spherical high-quality resonator SP9703 and an Oxford Instruments liquid helium system. The modulation frequency was $100 \mathrm{kHz}$. Accurate $g$ values were obtained using the built-in microwave frequency counter and a 2,2-diphenyl-1-picrylhydrazyl powder standard, the $g$ value for which is $g=2.0027 \pm 0.0002^{22,23}$.

\section{Results}

Optical characteristics of cytoglobin distal mutation

The expression of WT Cygb displays mixed monomer and dimer conformations as previously described ${ }^{20}$. However, the expressed $\mathrm{H} 81 \mathrm{~V}$ and H81Y mutants were predominantly monomeric as shown in the protein elution profiles from gel filtration (Figure 1A). Herein only monomeric protein was used in this study. The circular
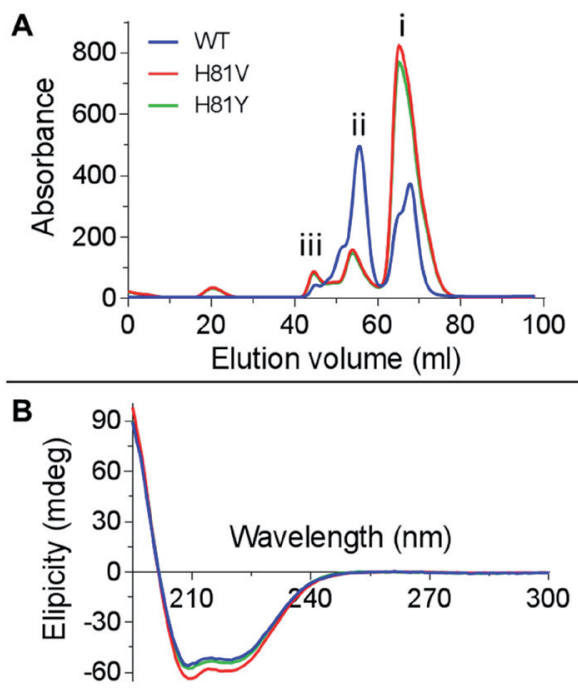

Figure 1. Cytoglobin mutant conformation and secondary structure. (A) Size exclusion chromatography (G-75 Superdex) of recombinant WT cytoglobin showing two major peaks, (i) at $56 \mathrm{ml}$ corresponding to the $43 \mathrm{kDa}$ dimer and (ii) at $67 \mathrm{ml}$ corresponding to the $21 \mathrm{kDa}$ monomer respectively. A small peak at $\sim 45 \mathrm{ml}$ corresponding to a minor fraction of polymerised Cygb. The mutant Cygb show the same peaks, however the peak corresponding the monomer (i) is the most prominent. (B) CD spectra of Cygb distal histidine mutants displaying characteristic double minima at 209 and $222 \mathrm{~nm}$ identifying $\alpha$-helical content. dichroism (CD) spectra of Cygb distal histidine mutants are shown in Figure 1B. All proteins display the typical double minima at 209 and $222 \mathrm{~nm}$ characteristic of protein structures that is predominantly $\alpha$-helical, essentially identical to the WT protein as previously reported ${ }^{24}$. Therefore the mutations did not significantly alter the secondary structure and the recombinant protein has folded correctly.

The optical spectra of Cygb are shown in Figure 2A in the ferric, deoxyferrous and ferrous-CO bound forms. These spectra are typical of those previously shown for the WT protein ${ }^{19,24}$. The ferrous-CO
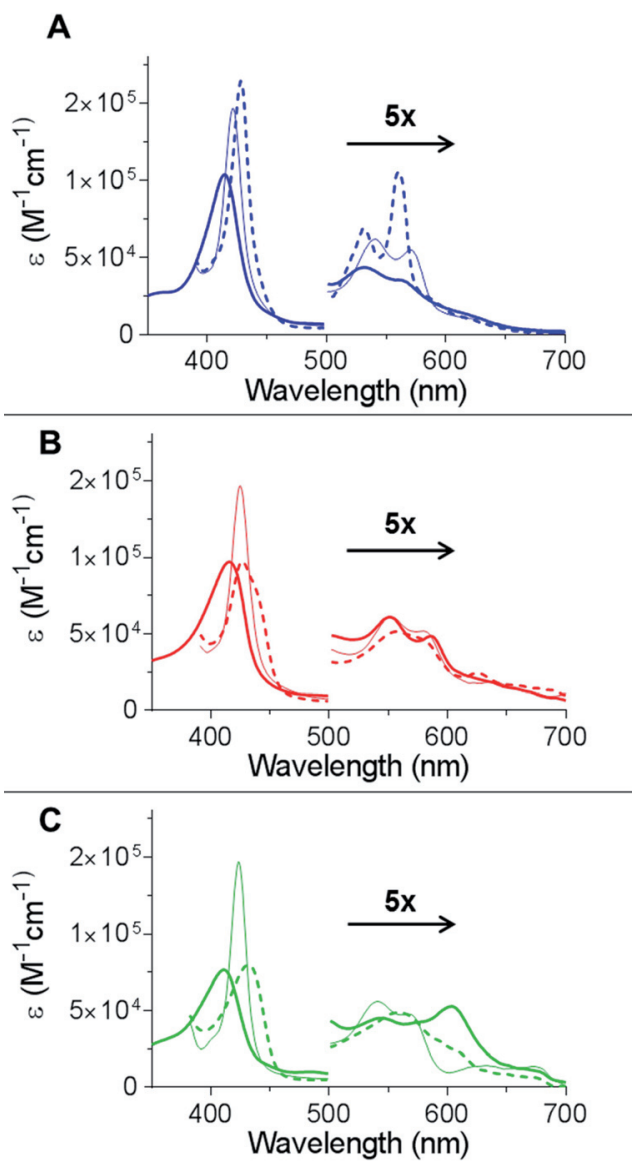

Figure 2. UV-Visible spectra of the WT cytoglobin and two distal histidine mutants. (A) The optical spectra of WT monomeric Cygb as previously described ${ }^{20}$. (B) The optical spectra of H81V Cygb. The ferric (solid) has a Soret of $415 \mathrm{~nm}$ and low intensity $\alpha$ and $\beta$ peaks at 550 and $588 \mathrm{~nm}$ respectively. The reduction of the protein by dithionite (dashed) led to a bathochromic shift with a broadening of the Soret accompanied by appearance of a single broad $\alpha \beta$ peak. The binding of $\mathrm{CO}$ (thin solid) led to a hypsochromic shift of the Soret with an increase in intensity. This is accompanied with the appearance of the $\alpha$ and $\beta$ peaks to 580 and $550 \mathrm{~nm}$ respectively. (C) The optical spectra of H81Y Cygb. The ferric (solid) has a Soret of $411 \mathrm{~nm}$ and three peaks in the visible region at 500, 543 and $605 \mathrm{~nm}$. The reduction of the protein by dithionite (dashed) led to a bathochromic shift of the Soret accompanied by an appearance of a single $\alpha \beta$ band with a shoulder. The binding of $\mathrm{CO}$ (thin solid) led to a hypsochromic shift of the Soret with an increase in intensity. This is accompanied with the appearance of the $\alpha$ and $\beta$ peaks at 570 and $542 \mathrm{~nm}$ respectively. 
spectrum of H81V and H81Y Cygb is essentially identical to that of the WT protein with a Soret of $423 \mathrm{~nm}$ and $\alpha$ and $\beta$ peaks of 570 and $542 \mathrm{~nm}$ respectively ${ }^{19,24}$. Mutation of the distal histidine results in significant changes of the optical properties of the protein when in the absence of exogenous ligands (Figure 2B and Figure 2C respectively). In the deoxyferrous state both of the distal histidine mutants exhibit only a single $\alpha \beta$ band with a low intensity shoulder at higher wavelength in comparison to the WT which has two distinct peaks. The $\alpha$ and $\beta$ bands of the WT protein is characteristic of a hexacoordinated haem iron, similar to that observed in $\mathrm{Ngb}$ or cytochrome $\mathrm{c}^{3,25}$. The two mutant proteins deoxyferrous optical characteristics are more typical of a pentacoordinate haem iron ligation as seen in $\mathrm{Mb}$ and $\mathrm{Hb}^{11}$. However, the broad Soret band of deoxyferrous H81V Cygb is wider than observed with the H81Y protein and $\mathrm{Mb}$ or $\mathrm{Hb}$, suggesting that $\mathrm{H} 81 \mathrm{~V}$ has a subpopulation of hexacoordinated species. In the ferric oxidation state the H81Y mutant displays three peaks in the visible region (Figure 2C) and exhibits a green appearance due to the $600 \mathrm{~nm}$ band compared to the orange-brown appearance of the other ferric proteins ${ }^{11}$. Other haem proteins with a distal tyrosine also display these characteristic absorbance peaks such as the homodimeric haemoglobin from Mycobacterium tuberculosis $(\mathrm{HbN})^{26}$ or in myoglobin with a distal tyrosine mutation ${ }^{27}$.

\section{EPR spectroscopy}

The EPR spectrum of monomeric ferric WT Cygb is shown in Figure 3 and is consistent with that previously reported ${ }^{20}$, comprising of a high spin (HS) signal at $g=5.95$, a low-spin (LS) signal at $\mathrm{g}=3.15$ and a small component at $\mathrm{g}=4.3$ representative of iron ferric ion in rhombic coordination mainly originating from damaged haem $^{28}$. Both of the distal histidine mutants exhibit different EPR spectra to the WT monomer. WT Cygb is partially HS showing a weak distal histidine coordination in the ferric form of the protein as previously described ${ }^{19,20}$. In the H81V mutant the HS signal is much greater compared to the WT protein, indicating the H81V is primarily pentacoordinate in the ferric state. This is also the case for the H81Y variant. Although the HS signal intensity for the H81Y appears lower, there is a notable contribution from the rhombic HS ferric haem signal with $g_{x}=6.68$ and $g_{y}=5.39$ which makes the whole EPR signal wider than the axial EPR line at $g_{\perp}=5.95$. This accounts for a higher spin concentration at a similar intensity of the EPR signal.

Unlike WT Cygb, the mutants do not exhibit the broad LS ferric haem form spectrum with $g=3.15$, which accounts for a significant fraction of protein in the WT. There is a different LS ferric haem EPR signal seen in both mutants, with $g=2.76$ and $g=2.29$. The concentration of this haem form is 5.2 times higher in the H81V mutant as compared to the H81Y mutant. The g-factors of this LS ferric haem form are close to some bis-His LS forms observed in other proteins $\mathrm{s}^{29,30}$. We speculate that a different residue can be the cause of this LS ferric haem state, likely resulting from a nitrogen ligand that can be positioned at the 6th haem coordination site. The best candidate for such a residue is the nearby arginine (R84). One can speculate why a LS ferric haem EPR signal is stronger in the valine mutant compared with the tyrosine mutant - most likely because tyrosine is larger allowing lower R84 occupancy.

\section{Peroxidase activity and reaction kinetics}

The reaction of WT Cygb with hydrogen peroxide does not form a ferryl species that can be monitored by standard optical spectroscopy, unlike other haem proteins such as $\mathrm{Mb}$ and $\mathrm{Hb}^{17,31}$. Therefore the peroxidatic activity was monitored using the guaiacol peroxidase activity assay which uses guaiacol as a substrate for ferryl

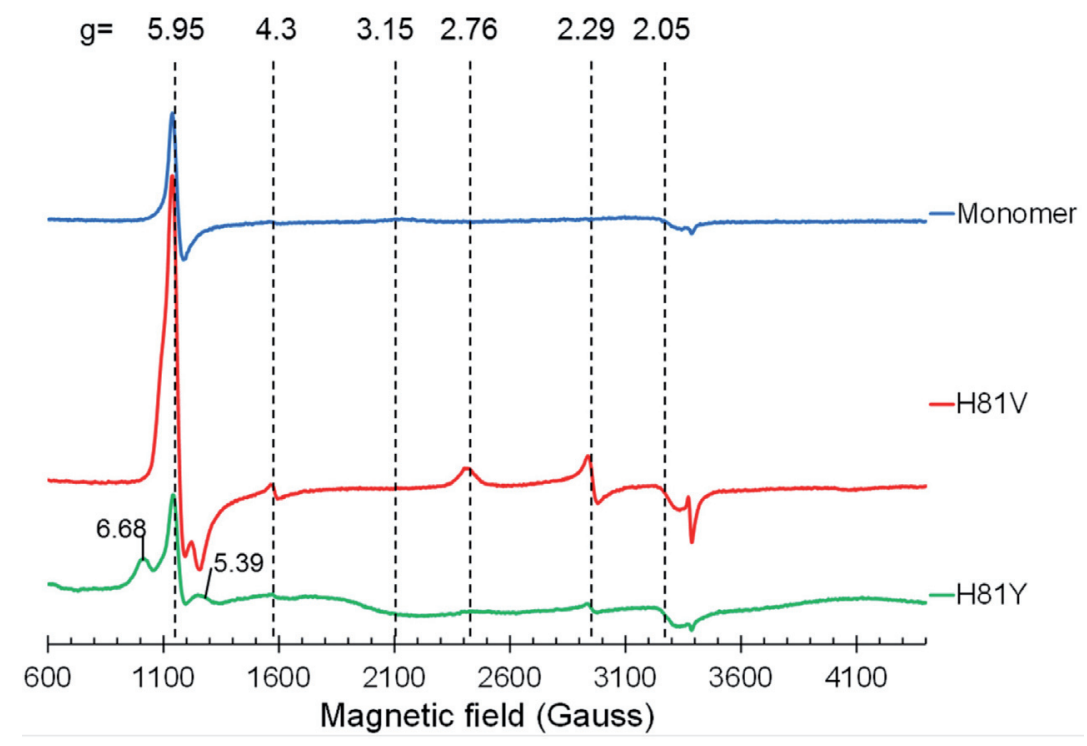

Figure 3. EPR spectra of cytoglobin distal histidine mutants. EPR spectra of ferric cytoglobin ( $80 \mu \mathrm{M})$ : wild type monomer with internal disulfide bond (upper spectrum), histidine 81(E7) to valine mutation (middle spectrum) and histidine 81 to tyrosine mutation (lower spectrum). The wild type protein is predominantly in a HisF8-Fe(III)-HisE7 co-ordination $\left(g_{3}=3.20, g_{2}=2.05, g_{1}\right.$ is off scale) as previously reported ${ }^{19}$. The H81V protein is mainly high spin with a HisF8-Fe(III)- $\mathrm{H}_{2} \mathrm{O}$ configuration with a minor (but sharper) LS component $\left(g_{3}=2.76, g_{2}=2.29, g_{1}\right.$ is off scale). The H81Y protein is again predominantly HS ferric haem rhombic signal with $\mathrm{g}=6.68$ and $\mathrm{g}=5.39$. 
Cygb, generating a tetrameric oxidation product of guaiacol that can be monitored at $470 \mathrm{~nm}$ (Figure $4 \mathrm{~A}$ ) ${ }^{32}$. The formation of the tetrameric oxidation product of guaiacol following the reaction of $\mathrm{H} 81 \mathrm{~V}$ and $\mathrm{H} 81 \mathrm{Y}$ with hydrogen peroxide is negligible in comparison to the WT protein (figure 4D). This initially suggests that there is limited ferryl formation at the peroxide concentration studied $(5 \mathrm{mM})$. However, the bleaching of the haem moiety, which is particularly rapid with the $\mathrm{H} 81 \mathrm{~V}$ protein, signifies that the guaiacol is not reacting with the ferryl haem iron hence radical damage from redox cycling is prominent. Therefore an alternative method was used to attempt to measure the formation of ferryl haem iron directly using stopped-flow spectroscopy.

The reaction of monomeric Cygb with high concentrations of hydrogen peroxide (1 to $10 \mathrm{mM}$ ) displayed monophasic time course (Figure 5A). The spectrum of the ferryl species has a Soret peak of $418 \mathrm{~nm}$ and $\alpha$ and $\beta$ peaks of 562 and $542 \mathrm{~nm}$ respectively (Figure $5 \mathrm{~B}$ ), consistent with the spectrum of ferryl $\mathrm{Mb}^{31}$. The rate of formation of the ferryl species was hydrogen peroxide concentration dependent with a second order rate constant of $312.3 \pm 16.3 \mathrm{M}^{-1} \mathrm{~S}^{-1}$ (Figure $5 \mathrm{C}$ ). This value is very similar to previously reported values of the second order rate constant of myoglobin reacting with hydrogen peroxide $\left(170 \mathrm{M}^{-1} \mathrm{~s}^{-133}\right.$ and $\left.267 \mathrm{M}^{-1} \mathrm{~s}^{-116}\right)$. There were no changes in amplitude in response to hydrogen peroxide concentration.

The reaction of the distal histidine mutants with hydrogen peroxide showed no measurable formation of ferryl haem iron, with the main optical changes indicative of haem degradation from radical damage (Figure 6A-C). There is a transient increase in absorbance at $\sim 600-700 \mathrm{~nm}$ for $\mathrm{H} 81 \mathrm{~V}$, which may be suggestive of an oxidative modified intermediate species.

Peroxide-induced damage to cytoglobin protein and haem To monitor radical damage to the haem of $\mathrm{Cygb}$, the protein $(50 \mu \mathrm{M})$ was reacted with hydrogen peroxide $(0-5 \mathrm{mM})$ at $25^{\circ} \mathrm{C}$ and the oxidative damage to the protein assessed after reaction was complete by HPLC analysis and gel electrophoresis. The HPLC results (Figure 7) show that WT Cygb is more resistant to haem damage compared to $\mathrm{Mb}$, with $2500 \mu \mathrm{M}$ peroxide required to degrade or modify $50 \%$ of the haem compared to $500 \mu \mathrm{M}$ for $\mathrm{Mb}$. However, the distal histidine mutants were more susceptible to peroxide induced haem damage than the WT protein with $\mathrm{H} 81 \mathrm{Y}$ showing $50 \%$ haem damage at $500 \mu \mathrm{M}$ peroxide and $60 \mu \mathrm{M}$ for $\mathrm{H} 81 \mathrm{~V}$ ( 1:1 peroxide: protein ratio). Interestingly $\mathrm{Mb}$ and $\mathrm{H} 81 \mathrm{Y}$ show identical resistance to peroxide induced haem damage at all peroxide concentrations studied.

The non-reducing PAGE analysis of monomeric Cygb before hydrogen peroxide treatment showed two bands that correspond to the monomeric protein, one with an intramolecular disulfide bond and the other with a reduced disulfide bond (Figure 8A) as described previously ${ }^{20}$. These bands lose intensity upon reaction with low concentrations of hydrogen peroxide $(50-100 \mu \mathrm{M})$ accompanied with the appearance of bands representative of dimeric and higher order conformers. At hydrogen peroxide concentrations above $1 \mathrm{mM}$ the protein forms aggregates as shown by minimal gel migration.

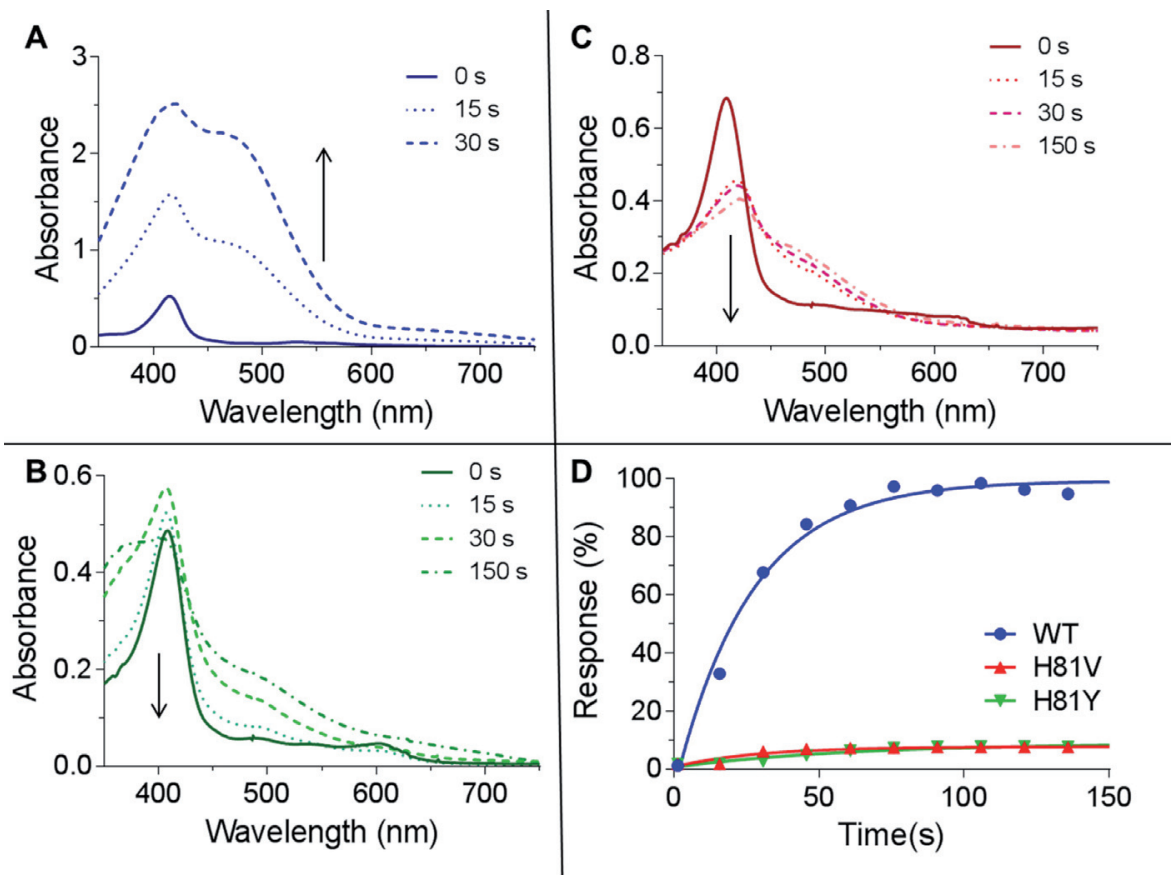

Figure 4. Peroxidase activity of cytoglobin distal histidine mutants using guaiacol oxidation assay. (A) Spectra of the oxidation of guaiacol $(8.9 \mathrm{mM})$ from the reaction of WT Cygb $(5 \mu \mathrm{M})$ and $\mathrm{H}_{2} \mathrm{O}_{2}(5 \mathrm{mM})$, showing the rapid formation of tetrameric guaiacol. (B and $\left.\mathbf{C}\right)$ Conditions are for those described in $(\mathbf{A})$ except with $\mathrm{H} 81 \mathrm{~V}(\mathbf{B})$ and $\mathrm{H} 81 \mathrm{Y}(\mathbf{C})$ variants of Cygb. There is little guaiacol oxidation observed but extensive haem bleaching within the time course of the experiment. (D) Time course of guaiacol oxidation showing a high peroxidase activity of WT Cygb. 

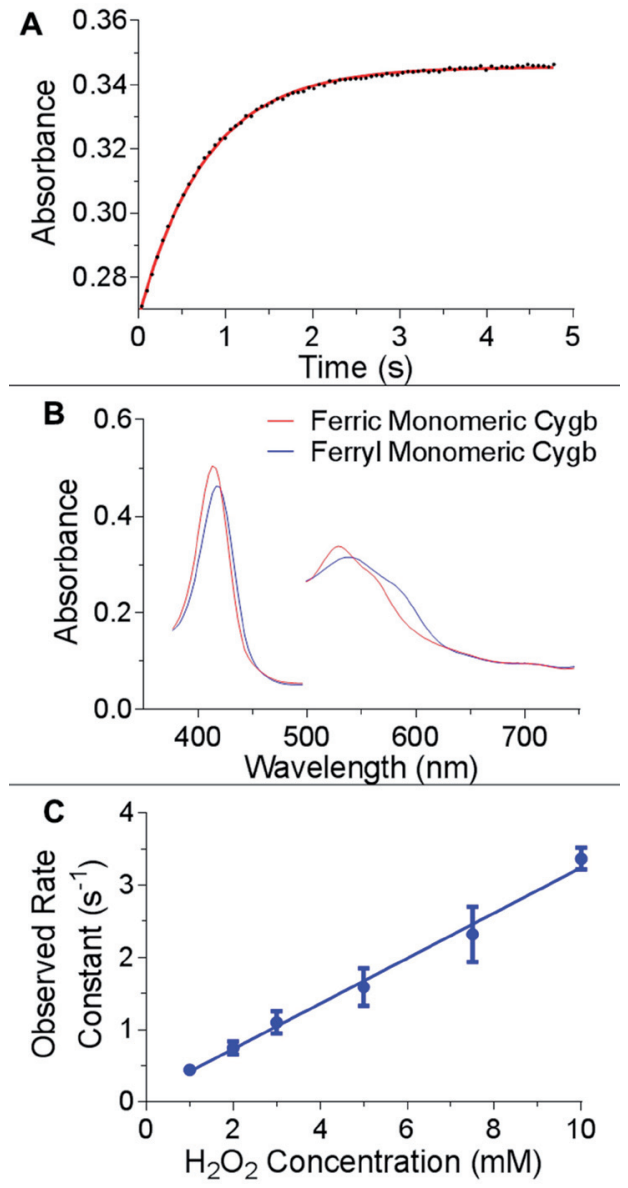

Figure 5. Ferryl formation of cytoglobin distal histidine mutants monitored by rapid reaction kinetics. (A) Time course of monomeric WT Cygb $(5 \mu \mathrm{M})$ reacting with $\mathrm{H}_{2} \mathrm{O}_{2}(5 \mathrm{mM})$. The changes in absorbance at $420 \mathrm{~nm}$ over time were fitted to a single exponential. (B) UV-visible changes observed during the reaction of monomeric Cygb $(5 \mu \mathrm{M})$ with $5 \mathrm{mM} \mathrm{H}_{2} \mathrm{O}_{2}$, identifying the ferryl species of Cygb with a Soret peak of $418 \mathrm{~nm}$ and $\alpha$ and $\beta$ peaks of 542 and $562 \mathrm{~nm}$ respectively. (C) The hydrogen peroxide concentration dependence on ferryl formation observed rate constants of monomeric WT Cygb $(5 \mu \mathrm{M})$ giving a second order rate constant of $312.3 \pm 16.3 \mathrm{M}^{-1} \mathrm{~s}^{-1}$.

Both of the distal histidine mutants exhibit bands similar to that of the WT monomeric protein showing the presence and absence of an intramolecular disulfide bond (Figure 8B and Figure 8C). The mutants appear to be more resistant to peroxide induced protein damage than the WT with significant concentrations of the monomeric forms at even $5 \mathrm{mM}$ peroxide (100x excess). There is dimerization of the mutant proteins at hydrogen peroxide ratios as low as 1:1 (protein:peroxide) similar to the WT protein. These dimers are still apparent at high peroxide concentrations in the mutant protein unlike the WT Cygb.

Monitoring the same reaction products using reducing gels (SDSPAGE, Figure 8D-F) showed a well-defined band at $\sim 21 \mathrm{kDa}$ indicative of monomeric Cygb. In comparison with the non-denaturing gels the monomer and dimer bands lose intensity with increasing
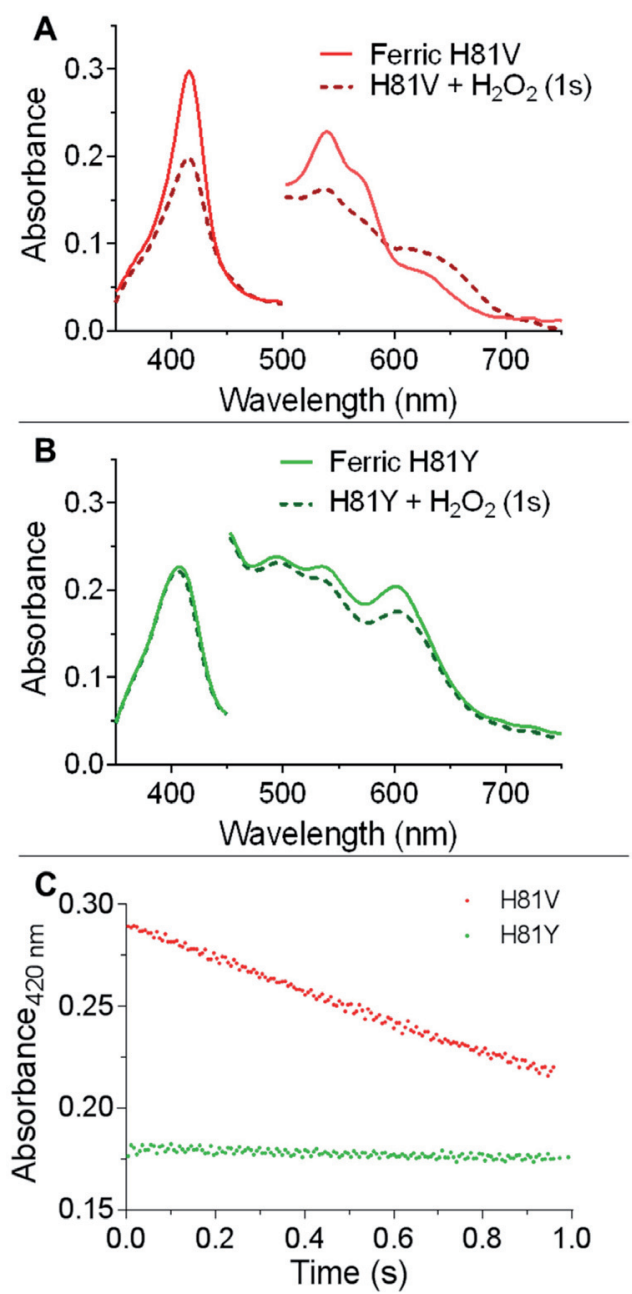

Figure 6. Cytoglobin distal histidine mutants reaction with hydrogen peroxide. (A) UV-visible changes of H81V $(5 \mu \mathrm{M})$ due to the reaction with $100 \mathrm{mM} \mathrm{H}_{2} \mathrm{O}_{2}$ over the time course of $1 \mathrm{~s}$. (B) UV-visible changes of H81Y (5 $\mu \mathrm{M})$ due to the reaction with $100 \mathrm{mM}$ $\mathrm{H}_{2} \mathrm{O}_{2}$ over the time course of $1 \mathrm{~s}$. (C) Time course of $\mathrm{H} 81 \mathrm{~V}$ and $\mathrm{H} 81 \mathrm{Y}$ $(5 \mu \mathrm{M})$ reacting with $\mathrm{H}_{2} \mathrm{O}_{2}(40 \mathrm{mM})$. The changes in absorbance at $420 \mathrm{~nm}$ over time were fitted linearly.

peroxide concentrations, which is more evident in the WT protein relative to the mutants. As the denaturing gel eliminates disulfide bonds the peroxide-induced formation of dimers and higher oligomers are likely to arise from covalent di-tyrosine links resulting from the termination of surface-exposed tyrosine radicals on two or more protein chains as have been reported for $\mathrm{Mb}$ and $\mathrm{Hb}^{34,35}$.

Peroxide-induced radical formation and stability

EPR spectra of the radicals formed from the reaction of Cygb with $\mathrm{H}_{2} \mathrm{O}_{2}$ are shown in Figure 7C. All proteins studied react with hydrogen peroxide to form protein-based radicals. However, the shape of the radical signal in WT differs significantly from the two mutants. While the WT radical exhibits a doublet-like EPR signal, the two mutants show a singlet EPR signal. An EPR signal that lacks a 

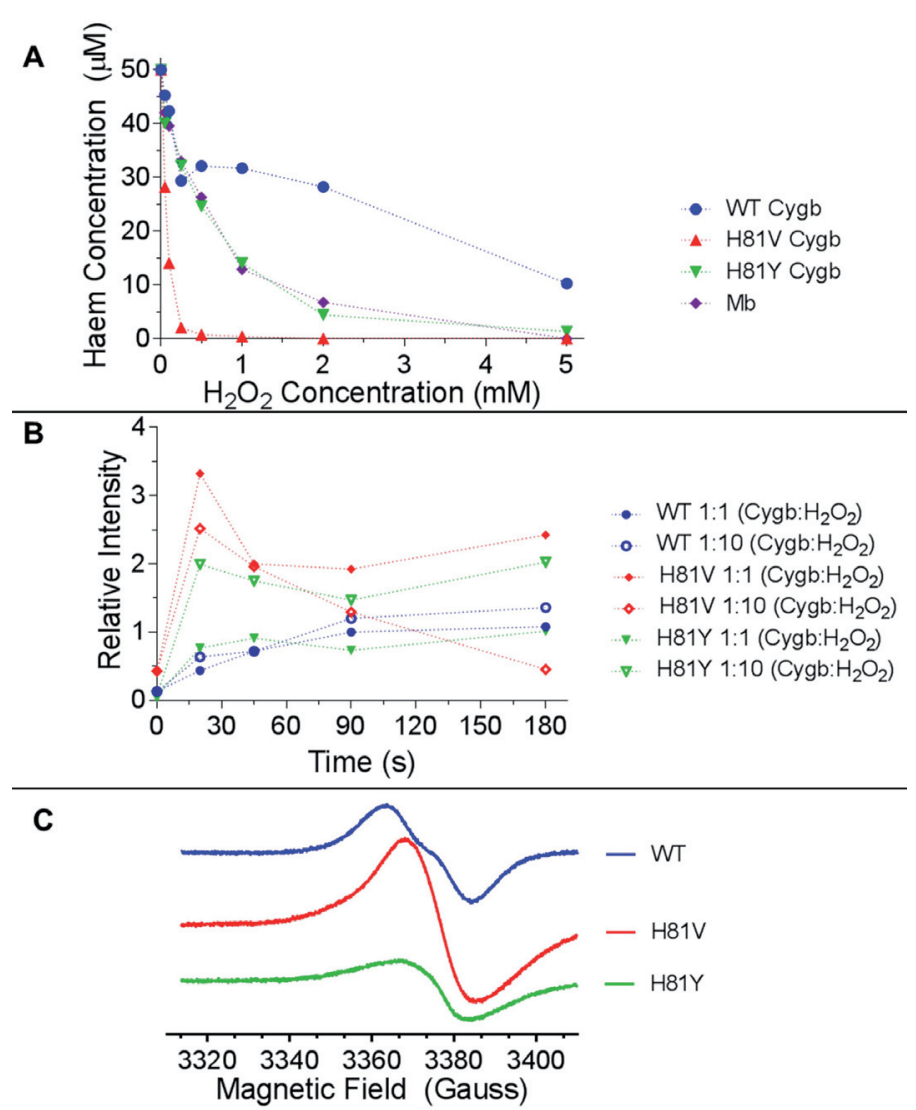

Figure 7. Effect of distal histidine mutation on peroxide-induced haem degradation and radical formation. (A) HPLC analysis of cytoglobin $(50 \mu \mathrm{M})$ following reaction with $\mathrm{H}_{2} \mathrm{O}_{2}(0-5 \mathrm{mM})$ showing unmodified haem concentration. (B) Time course of radical concentration formed in the reaction of cytoglobin $\left(80 \mu^{2} \mathrm{M}\right)$ and $\mathrm{H}_{2} \mathrm{O}_{2}$ (at either 1:1 or 1:10 molar excess), as measured by the EPR spectroscopy. (C) Example EPR spectra ( $t=90 \mathrm{~s}$ ) exhibiting a primarily doublet radical line shape of WT cytoglobin compared to the singlet line shape of H81Y and H81V.

hyperfine structure is always difficult to interpret. However, with respect to the $15-18 \mathrm{G}$ wide singlet EPR spectrum of the mutants, it should be noted that similar EPR signals of protein-bound free radicals have been reported in a number of occasions and were recently interpreted as superposition of several non-specific protein radicals formed as a result of disperse radical propagation during the radical character decay process ${ }^{36}$. The WT monomer Cygb, on the other hand, shows a doublet-like EPR line shape pointing to a possibility that the radical originates more likely from a single site on the protein, rather than many different sites. The formation rate and stability of the protein radical for WT and H81Y proteins are essentially identical for both $1: 1$ and 1:10 protein:peroxide ratios and are stable over the period of 180 seconds examined. The formation rate of the radical in the $\mathrm{H} 81 \mathrm{~V}$ protein is marginally larger but the radical itself is less stable.

Dataset 1. Data for peroxidatic activity of monomeric cytoglobin http://dx.doi.org/10.5256/f1000research.5971.d45066

Detailed descriptions of each data file can be found in the text file 'Data description' provided.

\section{Discussion}

This study shows Cygb as having a high peroxidase-like activity in comparison to other pentacoordinate globins such as Mb. This is in contrast to previous reports that Cygb has a no appreciable peroxidase activity ${ }^{37}$. This discrepancy could be explained by the different conformations of $\mathrm{Cygb}$, with the current study using the monomeric protein with an internal disulfide bond between C38 and C83. Previous studies have not identified the conformation of the protein under investigation. We have previously shown that this disulfide bond is important for the biochemical properties of the protein with differences reported for ligand binding and redox chemistry ${ }^{20}$. The nature of the Cygb conformation in vivo is unknown, however, at micromolar concentrations the protein is monomeric ${ }^{38}$, which is consistent with the cellular concentrations.

Previous studies with Cygb have shown that mutation of the distal histidine affects ligand binding ${ }^{24}$. The reaction of WT Cygb with peroxide showed the formation of the transient ferryl species (Figure 5) and ferric-ferryl redox cycling (Figure 4). This is in contrast to the H81V and H81Y mutants that appear not to exhibit ferryl or any significant guaiacol oxidation $(<5 \%$ compared to WT). The lack of a distal histidine in Mb leads to a transient formation of peroxide-bound species (Compound 0$)^{17}$, which is not observed 


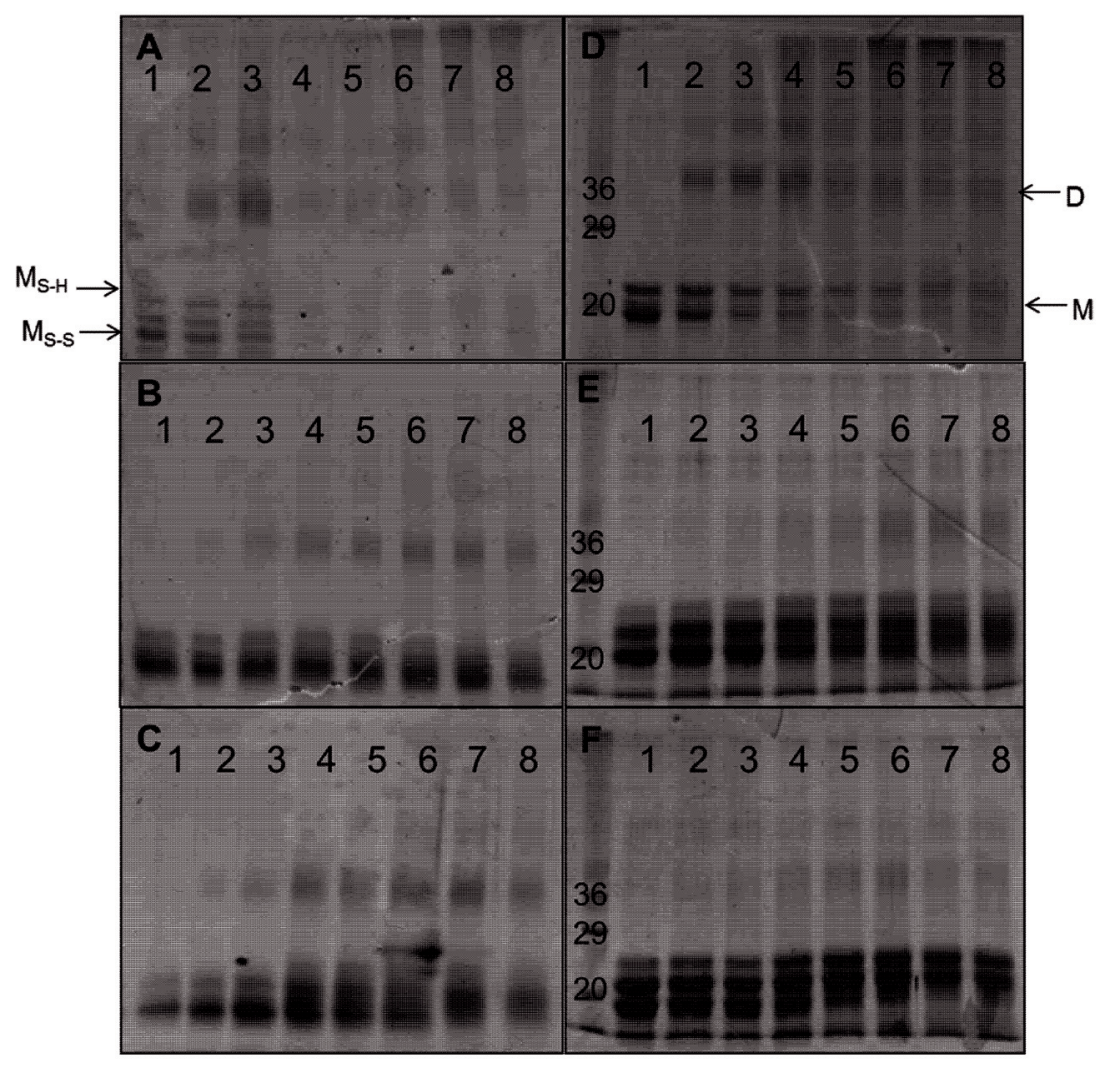

Figure 8. Gel electrophoresis of product of cytoglobin distal histidine variants following the reaction with hydrogen peroxide. Cygb $(50 \mu \mathrm{M})$ was reacted for 18 hours with $0,50,100,250,500,1000,2500,5000 \mu \mathrm{M} \mathrm{H}_{2} \mathrm{O}_{2}$ (lanes 1-8 respectively). SDS-PAGE analysis of WT, H81V and H81Y Cygb are shown in A, B and $\mathbf{C}$ respectively and non-reducing PAGE analysis of WT, H81V and H81Y Cygb are shown in D, $\mathbf{E}$ and $\mathbf{F}$ respectively. The monomer and dimer conformations are shown as (M) and (D) respectively.

with our mutants of Cygb. However, the rapid degradation of haem as reported in the mutants by HPLC, stopped flow and EPR spectroscopy supports a conjecture that the proteins react fast with peroxide, but the ferryl formed in the reactions is extremely unstable as it is not observed in the millisecond timescale. This suggests that the lack of guaiacol oxidation in the H81V and H81Y proteins is due to the inability of the guaiacol to donate an electron to the ferryl before it decays. The instability of the ferryl could account for the extensive haem and protein damage and is in agreement with extensive protein radical formation on multiple free radical sites in the mutants as compared to the WT, resulting in unresolved singlet EPR signal (Figure 7 and Figure 8).

The introduction of a tyrosine at the distal site increases resistance to peroxide-induced haem degradation as compared to valine, but degradation of the H81Y is still higher than that of the WT. This is likely due to the access to the haem being sterically hindered more by the larger cyclic amino acid. The polarity of the distal residue has also been suggested to affect the reaction with $\mathrm{H}_{2} \mathrm{O}_{2}$ - by providing a hydrogen bond to the ligand at the distal site ${ }^{17}$. Both mutants show a partial low spin form (Figure 3). This is not wholly unexpected for the H81Y mutant as the tyrosine could coordinate to the haem iron. However, the LS signal for this species is identical to that observed with H81V (but with different intensity), suggesting that another residue is coordinating to the iron. The EPR signal is similar to that observed in distal histidine mutants of $\mathrm{Ngb}^{39}$. The identity of this residue is unknown, however; a nearby arginine (R84) is a position to potentially coordinate to the haem iron.

In summary, our study identifies the requirement of the distal histidine for the formation of a ferryl species in monomeric Cygb and prevention of rapid haem degradation by free radical activity. This is similar to what has been reported for distal histidine mutations $(\mathrm{H} 64 \mathrm{Q} / \mathrm{H} 64 \mathrm{~V})$ in $\mathrm{Mb}^{17}$. Monomeric Cygb with the internal disulfide bound has a weaker coordination of the distal histidine and is therefore more pentacoordinate-like. This is consistent with the EPR data (Figure 3) that show partial penta-coordination which can also be increased through lipid binding ${ }^{19,20}$. This pentacoordinate-like nature of the Cygb allows for the reaction with peroxide, which is not observed with fully hexacoordinate $\mathrm{Ngb}$. Although the ferryl Cygb is more unstable compared to this haem oxidation state in other pentacoordinate globins, the distal histidine introduces a resistance to free radical damage above that of other globins that show peroxidatic activity. These findings are consistent with a potential peroxidatic-like role of monomeric Cygb in vivo. 


\section{Data availability}

F1000Research: Dataset 1. Data for peroxidatic activity of monomeric cytoglobin, 10.5256/f1000research.5971.d45066 ${ }^{40}$

\section{Author contributions}

Penny Beckerson and Brandon Reeder planned the experiments. Penny Beckerson performed most of the experiments assisted by Dimitri Svistunenko with the EPR data (Figure 3 and Figure 7C). Brandon Reeder designed and supervised the project. Penny Beckerson, Dimitri Svistunenko and Brandon Reeder analysed the data and wrote the paper. All authors contributed to the revision of the paper and proofread before submission.

\section{Competing interests}

No competing interests were disclosed.

\section{Grant information}

The author(s) declared that no grants were involved in supporting this work.

Acknowledgements

We thank Prof. Michael T. Wilson for useful discussions.
1. Trent JT 3rd, Hargrove MS: A ubiquitously expressed human hexacoordinate hemoglobin. J Biol Chem. 2002; 277(22): 19538-45. PubMed Abstract | Publisher Full Text

2. Burmester T, Ebner B, Weich B, et al.: Cytoglobin: a novel globin type ubiquitously expressed in vertebrate tissues. Mol Biol Evol. 2002; 19(4): 416-21. PubMed Abstract | Publisher Full Text

3. Dewilde $\mathrm{S}$, Kiger L, Burmester $\mathrm{T}$, et al.: Biochemical characterization and ligand binding properties of neuroglobin, a novel member of the globin family. J Biol Chem. 2001; 276(42): 38949-55.

PubMed Abstract | Publisher Full Text

4. Sawai $\mathrm{H}$, Makino M, Mizutani $\mathrm{Y}$, et al: Structural characterization of the proximal and distal histidine environment of cytoglobin and neuroglobin. Biochemistry. 2005; 44(40): 13257-65.

PubMed Abstract | Publisher Full Text

5. Fang J, Ma I, Allalunis-Turner J: Knockdown of cytoglobin expression sensitizes human glioma cells to radiation and oxidative stress. Radiat Res. 2011; 176(2): 198-207.

PubMed Abstract | Publisher Full Text

6. Li D, Chen X, Li WJ, et al:: Cytoglobin up-regulated by hydrogen peroxide plays a protective role in oxidative stress. Neurochem Res. 2007; 32(8): 1375-80. PubMed Abstract | Publisher Full Text

7. Gardner AM, Cook MR, Gardner PR: Nitric-oxide dioxygenase function of human cytoglobin with cellular reductants and in rat hepatocytes. $J$ Biol Chem. 2010; 285(31): 23850-7.

PubMed Abstract | Publisher Full Text | Free Full Text

8. Mimura I, Nangaku M, Nishi $\mathrm{H}$, et al.: Cytoglobin, a novel globin, plays an antifibrotic role in the kidney. Am J Physiol Renal Physiol. 2010; 299(5): F1120-F33.

PubMed Abstract | Publisher Full Text

9. Kawada N, Kristensen DB, Asahina K, et al.: Characterization of a stellate cell activation-associated protein (STAP) with peroxidase activity found in rat hepatic stellate cells. J Biol Chem. 2001; 276(27): 25318-23. PubMed Abstract | Publisher Full Text

10. Hodges NJ, Innocent N, Dhanda S, et al:: Cellular protection from oxidative DNA damage by over-expression of the novel globin cytoglobin in vitro. Mutagenesis. 2008; 23(4): 293-8.

PubMed Abstract | Publisher Full Text

11. Antonini E, Brunori M: Hemoglobin and Myoglobin in their Reactions with Ligands. Neuberger A TE, editor. Amsterdam: North-Holland Publishing Company. 1971

Reference Source

12. George $\mathrm{P}$, Irvine $\mathrm{DH}$ : Reaction of methmyoglobin with hydrogen peroxide. Nature. 1951; 168(4265): 164-5.

PubMed Abstract | Publisher Full Text

13. Svistunenko DA, Reeder BJ, Wankasi MM, et al.: Reaction of Aplysia limacina metmyoglobin with hydrogen peroxide. Dalton Trans. 2007; (8): 840-50. PubMed Abstract | Publisher Full Text

14. Matsui T, Ozaki Si, Watanabe $\mathrm{Y}$ : On the formation and reactivity of compound of the His-64 myoglobin mutants. J Biol Chem. 1997; 272(52): 32735-8. PubMed Abstract | Publisher Full Text
15. Egawa $\mathrm{T}$, Shimada $\mathrm{H}$, Ishimura $\mathrm{Y}$ : Formation of compound $\mathrm{I}$ in the reaction of native myoglobins with hydrogen peroxide. J Biol Chem. 2000; 275(45): 34858-66.

PubMed Abstract | Publisher Full Text

16. Khan KK, Mondal MS, Padhy L, et al.: The role of distal histidine in peroxidase activity of myoglobin--transient-kinetics study of the reaction of $\mathrm{H}_{2} \mathrm{O}_{2}$ with wild-type and distal-histidine-mutanted recombinant human myoglobin. Eur $\mathrm{J}$ Biochem. 1998; 257(3): 547-55.

PubMed Abstract | Publisher Full Text

17. Brittain T, Baker AR, Butler CS, et al:: Reaction of variant sperm-whale myoglobins with hydrogen peroxide: the effects of mutating a histidine residue in the haem distal pocket. Biochem J. 1997; 326(pt 1): 109-15. PubMed Abstract | Free Full Text

18. Herold S, Fago A, Weber RE: Reactivity studies of the Fe(III) and Fe(II)NO forms of human neuroglobin reveal a potential role against oxidative stress. $J$ Biol Chem. 2004; 279(22): 22841-7.

PubMed Abstract | Publisher Full Text

19. Reeder BJ, Svistunenko DA, Wilson MT: Lipid binding to cytoglobin leads to a change in haem co-ordination: a role for cytoglobin in lipid signalling of oxidative stress. Biochem J. 2011; 434(3): 482-92. PubMed Abstract | Publisher Full Text

20. Beckerson P, Wilson MT, Svistunenko DA, et al.: Cytoglobin ligand binding regulated by changing haem-coordination in response to intramolecular disulfide bond formation and lipid interaction. Biochem J. 2015; 465(1): 127-37.

PubMed Abstract | Publisher Full Text

21. Reeder BJ, Svistunenko DA, Sharpe MA, et al:: Characteristics and mechanism of formation of peroxide-induced heme to protein cross-linking in myoglobin. Biochemistry. 2002; 41(1): 367-75.

PubMed Abstract | Publisher Full Text

22. Weil J, Bolton J, Wertz J: Electron Paramagnetic Resonance. Wiley, New York. 1994.

23. Reeder BJ, Grey M, Silaghi-Dumitrescu RL, et al:: Tyrosine residues as redox cofactors in human hemoglobin: implications for engineering nontoxic blood substitutes. J Biol Chem. 2008; 283(45): 30780-7.

PubMed Abstract | Publisher Full Text | Free Full Text

24. Sawai H, Kawada N, Yoshizato K, et al:: Characterization of the heme environmental structure of cytoglobin, a fourth globin in humans. Biochemistry. 2003; 42(17): 5133-42.

PubMed Abstract | Publisher Full Text

25. Shechter E, Saludjian P: Conformation of ferricytochrome c. IV. Relationship between optical absorption and protein conformation. Biopolymers. 1967; 5(8): 788-90.

PubMed Abstract | Publisher Full Text

26. Couture M, Yeh SR, Wittenberg BA, et al.: A cooperative oxygen-binding hemoglobin from Mycobacterium tuberculosis. Proc Natl Acad Sci U S A. 1999; 96(20): 11223-8.

PubMed Abstract | Publisher Full Text | Free Full Text

27. Hargrove MS, Singleton EW, Quillin ML, et al:: His64(E7)-->Tyr apomyoglobin as a reagent for measuring rates of hemin dissociation. J Biol Chem. 1994; 269(6): 
4207-14.

PubMed Abstract

28. de Groot JJ, Veldink GA, Vliegenthart JF, et al.: Demonstration by EPR spectroscopy of the functional role of iron in soybean lipoxygenase-1. Biochim Biophys Acta. 1975; 377(1): 71-9.

PubMed Abstract | Publisher Full Text

29. Wang J, Boldt NJ, Ondrias MR: Formation and photolability of low-spin ferrous cytochrome c peroxidase at alkaline pH. Biochemistry. 1992; 31(3): 867-78. PubMed Abstract | Publisher Full Text

30. Peisach J, Blumberg WE, Ogawa S, et al.: The effects of protein conformation on the heme symmetry in high spin ferric heme proteins as studied by electron paramagnetic resonance. J Biol Chem. 1971; 246(10): 3342-55. PubMed Abstract

31. King NK, Winfield ME: The mechanism of metmyoglobin oxidation. J Biol Chem 1963; 238(4): 1520-8. PubMed Abstract

32. Maehly A, Chance B: The assay of catalases and peroxidases. Methods Biochem Anal. 1954; 1: 357-424. PubMed Abstract | Publisher Full Text

33. Carlsen CU, Skovgaard IM, Skibsted LH: Pseudoperoxidase activity of myoglobin: kinetics and mechanism of the peroxidase cycle of myoglobin with $\mathrm{H}_{2} \mathrm{O}_{2}$ and 2,2-azino-bis(3-ethylbenzthiazoline-6-sulfonate) as substrates. $J$ Agric Food Chem. 2003; 51(19): 5815-23. PubMed Abstract | Publisher Full Text

34. Lardinois OM, de Montellano PR: Intra- and intermolecular transfers of protein radicals in the reactions of sperm whale myoglobin with hydrogen peroxide. $J$ Biol Chem. 2003; 278(38): 36214-26.

PubMed Abstract | Publisher Full Text

35. Lardinois OM, Ortiz de Montellano PR: Autoreduction of ferryl myoglobin: discrimination among the three tyrosine and two tryptophan residues as electron donors. Biochemistry. 2004; 43(15): 4601-10. PubMed Abstract | Publisher Full Text

36. Rajagopal BS, Edzuma AN, Hough MA, et al.: The hydrogen-peroxide-induced radical behaviour in human cytochrome c-phospholipid complexes: implications for the enhanced pro-apoptotic activity of the G41S mutant. Biochem J. 2013; 456(3): 441-52.

PubMed Abstract | Publisher Full Text

37. Trandafir F, Hoogewijs D, Altieri F, et al:: Neuroglobin and cytoglobin as potential enzyme or substrate. Gene. 2007; 398(1-2): 103-13. PubMed Abstract | Publisher Full Text

38. Lechauve $\mathrm{C}$, Chauvierre $\mathrm{C}$, Dewilde $\mathrm{S}$, et al:: Cytoglobin conformations and disulfide bond formation. FEBS J. 2010; 277(12): 2696-704

PubMed Abstract | Publisher Full Text

39. Uno T, Ryu D, Tsutsumi $\mathrm{H}$, et al:: Residues in the distal heme pocket of neuroglobin. Implications for the multiple ligand binding steps. J Biol Chem 2004; 279(7): 5886-93.

PubMed Abstract | Publisher Full Tex

40. Beckerson P, Svistunenko D, Reeder B: Dataset 1 in: Effect of the distal histidine on the peroxidatic activity of monomeric cytoglobin. F1000Research. 2015. Data Source 


\section{Open Peer Review}

\section{Current Peer Review Status:}

\section{Version 1}

Reviewer Report 01 May 2015

https://doi.org/10.5256/f1000research.6388.r8551

(C) 2015 Patel R. This is an open access peer review report distributed under the terms of the Creative Commons Attribution License, which permits unrestricted use, distribution, and reproduction in any medium, provided the original work is properly cited.

\section{Rakesh Pravinchandra Patel}

Department of Pathology and Center for Free Radical Biology and Lung Injury and Repair Center, University of Alabama at Birmingham, Birmingham, AL, USA

Cytoglobin in regulating redox reactions with $\mathrm{H} 2 \mathrm{O} 2$. The study design and methods used are appropriate to address the proposed questions. The data nicely show that distal His residues of this protein play key roles in maintaining heme stability during reactions with $\mathrm{H} 2 \mathrm{O} 2$.

1. Details of how many replicates and statistical analyses used to discern differences should be provided.

2. Is the heme loss observed after reactions with $\mathrm{H} 2 \mathrm{O} 2$ and His mutants due to heme release and/ or heme modification that in turn would preclude extraction and measurement by HPLC. The authors should provide some thoughts on how they think reactions with $\mathrm{H} 2 \mathrm{O} 2$ (in the His mutants) is causing the heme to be released or degraded?

3. Are the effects of the distal His exclusive for reactions with $\mathrm{H} 2 \mathrm{O} 2$ ? Could the authors speculate a little more on whether their results are more generalizable to other biologically relevant peroxides $(\mathrm{LOOH}, \mathrm{ONOO}(\mathrm{H})$ etc.).

Competing Interests: No competing interests were disclosed.

I confirm that I have read this submission and believe that I have an appropriate level of expertise to confirm that it is of an acceptable scientific standard.

Reviewer Report 28 April 2015

https://doi.org/10.5256/f1000research.6388.r8224 
(C) 2015 Hargrove $\mathbf{M}$. This is an open access peer review report distributed under the terms of the Creative Commons Attribution License, which permits unrestricted use, distribution, and reproduction in any medium, provided the original work is properly cited.

\section{Mark Hargrove}

Department of Biochemistry, Biophysics and Molecular Biology, Iowa State University, Ames, IA, USA

These authors have been publishing quality data with Cygb over the past few years, and the work presented here is a continuation of the same line of investigation. The experiments conducted are fairly straight forward, and the immediate results are clear (with the possible exception of Figure 7 , as discussed below), but the conclusions drawn from them are not as strong. The goal of the work was to test the hypothesis that Cygb might serve as a peroxidase in vivo. Since no one yet knows the actual function of Cygb in vivo, the present investigation must compare Cygb to something else. Two point mutants of Cygb and myoglobin are used for comparison.

Absorbance and EPR spectroscopy, along with reactions with $\mathrm{H} 2 \mathrm{O} 2$, and a guaiacol-based peroxidase assay provide the bulk of the data to test this hypothesis.

Interesting/positive points about this article: $\mathrm{Cygb}$ and $\mathrm{Mb}$ react differently in the guaiacol assay (Cygb actually doesn't react much at all). However, when an assay specific for formation of ferryl heme is used, both proteins react similarly (with respect to their bimolecular rate constants for the spectral change following mixing with $\mathrm{H} 2 \mathrm{O} 2$ ). This means that Cygb can be oxidized by $\mathrm{H} 2 \mathrm{O} 2$ just like $\mathrm{Mb}$, but does not then oxidize a substrate such as guaiacol, as does Mb.

Remaining questions/criticisms of the article: It is evident that interesting things happen when Cygb is mixed with $\mathrm{H} 2 \mathrm{O} 2$, and that different things happen to the two point mutants. It is not at all clear what is learned from the EPR spectra. The conclusion is that the introduced Tyr might occlude R84 coordination, but this is very speculative and has little to do with the point of this article.

Figure 7 is not an overwhelming endorsement of the stability of Cygb against hydrogen peroxide. The $\mathrm{H} 2 \mathrm{O} 2$ dependence of Cygb modification is very strange, at first responding like $\mathrm{Mb}$ (for the first four points of the curve), then resisting the approach to $50 \%$ reduction of unmodified heme until the reported value of $2500 \mu \mathrm{M}$. I think it is a bit misleading to judge these curves by the concentration of $\mathrm{H} 2 \mathrm{O} 2$ needed to damage $50 \%$ of the heme, when the does-response is so complex. For example, if the parameter used to measure $\mathrm{Mb}$ versus Cygb were "concentration of $\mathrm{H} 2 \mathrm{O} 2$ needed to damage $40 \%$ of the heme", Mb and Cygb would be the same.

Why in the discussion is it said that Cygb has a higher peroxidase activity than Mb? As measured by guaiacol, it does not, and as measured by the formation of the ferryl species, it is the same. Furthermore, the final conclusion for how these data test the primary hypothesis is that they are "consistent with a potential peroxidatic-like role of monomeric Cygb in vivo". While these results are interesting, I am not sure how they could fail in support of this hypothesis, short of Cygb not reacting at all with $\mathrm{H} 2 \mathrm{O} 2$. Based on the data reported here, these results also support a role for $\mathrm{Mb}$ having a peroxidatic-like activity in vivo. 
Competing Interests: No competing interests were disclosed.

I confirm that I have read this submission and believe that I have an appropriate level of expertise to confirm that it is of an acceptable scientific standard.

The benefits of publishing with F1000Research:

- Your article is published within days, with no editorial bias

- You can publish traditional articles, null/negative results, case reports, data notes and more

- The peer review process is transparent and collaborative

- Your article is indexed in PubMed after passing peer review

- Dedicated customer support at every stage

For pre-submission enquiries, contact research@f1000.com 